\title{
Asymptomatic saccular portal vein aneurysm: a case report and review of the literature
}

\author{
Rosanna Villani ${ }^{1}$ (D) $\cdot$ Pierluigi Lupo ${ }^{2} \cdot$ Anna Grazia Angeletti $^{1} \cdot$ Antonia Federica Sacco $^{1} \cdot$ Luca Macarini $^{2}$. \\ Gaetano Serviddio ${ }^{1}$
}

Received: 15 October 2021 / Accepted: 12 January 2022 / Published online: 3 February 2022

(c) The Author(s) 2022

\begin{abstract}
Portal vein aneurysms are rare abnormal dilations of the portal vein and represent less than $3 \%$ of all visceral aneurysms. They may be congenital or acquired, symptomatic or asymptomatic, complicated or uncomplicated. Portal vein aneurysms may be fusiform or saccular and this last one has a low prevalence. Due to the small number of cases reported in the medical literature and the lack of specific guidelines, the management and treatment of this condition is still undefined. In this review, we report a case of saccular portal vein aneurysm in a 73-year old man with liver cirrhosis and discuss all cases of portal vein aneurysms reported in literature.
\end{abstract}

Keywords Ultrasound $\cdot$ Portal vein $\cdot$ Aneurysm

\section{Introduction}

Portal vein aneurysm is the abnormal dilation of the portal vein and is defined as a portal vein diameter exceeding the $19 \mathrm{~mm}$ in cirrhotic patients and $15 \mathrm{~mm}$ in normal livers [1].

It was firstly described in 1956 by Barzilai and Kleckner, and since then, only less than 200 cases have been reported [1].

It represents less than $3 \%$ of all visceral aneurysms and etiology is still unknown, even if two forms are generally considered: congenital and acquired [2].

The main cause of the acquired form is liver cirrhosis complicated by portal hypertension [3]. In these patients, hyperdynamic circulation or portal vein invasion by malignancy is involved in the pathogenesis.

Portal vein aneurysms may be fusiform or saccular; fusiform aneurysms are more common than saccular aneurysms, however these last ones are more likely to have complications [4].

Rosanna Villani

rosanna.villani@unifg.it

1 University Centre for Liver Disease Research and Treatment, Liver Unit, Department of Medical and Surgical Sciences, University of Foggia, Foggia, Italy

2 Department of Radiology, University of Foggia, Foggia, Italy
We report a case of saccular portal vein aneurysm in a 73-year old male with alcohol-related cirrhosis. Portal vein aneurysm was acquired, uncomplicated and, moreover, the patient was asymptomatic.

We also performed a systematic literature search in PubMed and Scopus databases and discussed all case reports dealing with portal vein aneurysms.

\section{Case description}

A 73-year old male patient presented to the outpatient clinic of our Liver Unit. Patient's medical history included excessive alcohol intake (at least 10 drinks in a day for more than 10 years), moderate splenomegaly and thrombocytopenia $(112.000 / \mu \mathrm{L})$. Abdominal ultrasonographic examination revealed a hepatic coarse echo pattern, narrowed hepatic veins and increased portal vein diameter (14 mm). An hypoechoic area with a maximal diameter of $40 \mathrm{~mm}$ was detected next to the main trunk of the portal vein. A definite communication between this lesion and the main branch of the portal vein was observed. Color Doppler evaluation showed bidirectional, swirling, non-pulsatile and monophasic flow ("Korean flag" or "Yin-Yang" sign) within the hypoechoic area (Fig. 1). No signs of portal vein thrombosis were observed, whereas splenomegaly and mild ascites were also 

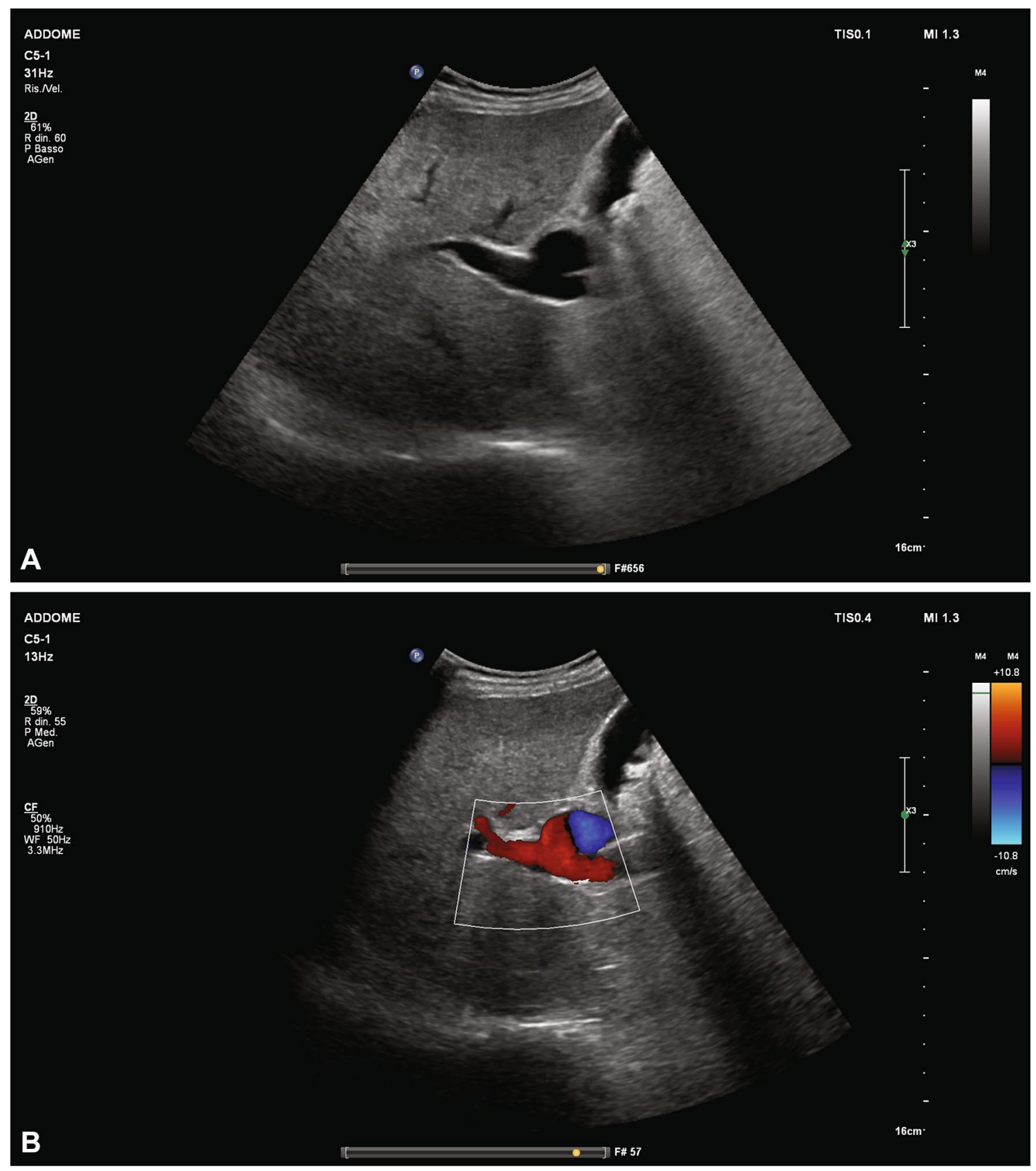

Fig. 1 B-mode ultrasound (A) and Color Doppler imaging (B) show the saccular aneurysm of the distal portal vein. B show the "Yin-Yan" sign resulting from the bidirectional flow to and from the saccular aneurysm

found. 2D and 3-D abdominal CT imaging confirmed the diagnosis (Figs. 2, 3).

\section{Discussion}

Portal venous aneurysms represent approximately 3\% of all venous aneurysms with a reported overall prevalence of $0.06 \%[2,5]$. The incidence has been increasing over time thanks to the use of modern imaging techniques in clinical practice.

Portal vein aneurysms are generally asymptomatic and diagnosed as incidental findings during ultrasound examinations. They can be congenital or acquired and various complications such as biliary tract compression, portal vein thrombosis, and rupture may occur over time [1].

Congenital aneurysms may develop after incomplete regression of vitellin vein because the development of portal vein is linked to the involution of the interconnections 

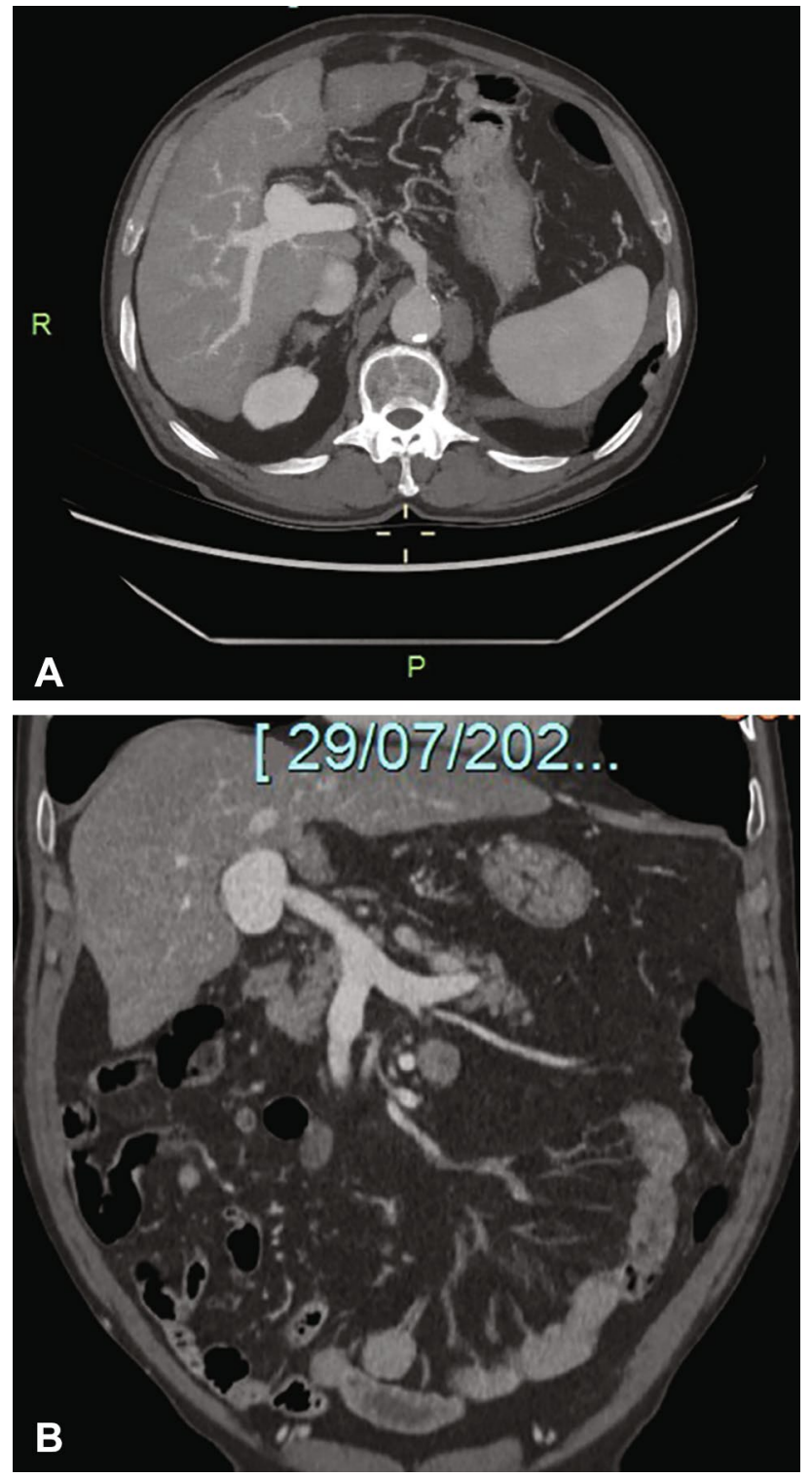

Fig. 2 Two-dimensional CT imaging. Transverse (A) and coronal (B) sections are shown

between the right and left vitelline veins. The incomplete involution of the distal part of the vitellin vein, followed by the formation of a diverticulum of the portal wall or the presence of a defect in the portal wall $[6,7]$ may be involved in the physiopathology of portal vein aneurysms. These theories are supported by the observation of congenital aneurysms in children [1].

On the other hand, chromosomal disorders seem not to be associated with portal vein aneurysm development. For this purpose, only one case by Sari et al. described a portal vein aneurysm in a 19-year old man with Klinefelter syndrome and abdominal pain, nausea and vomiting [8].
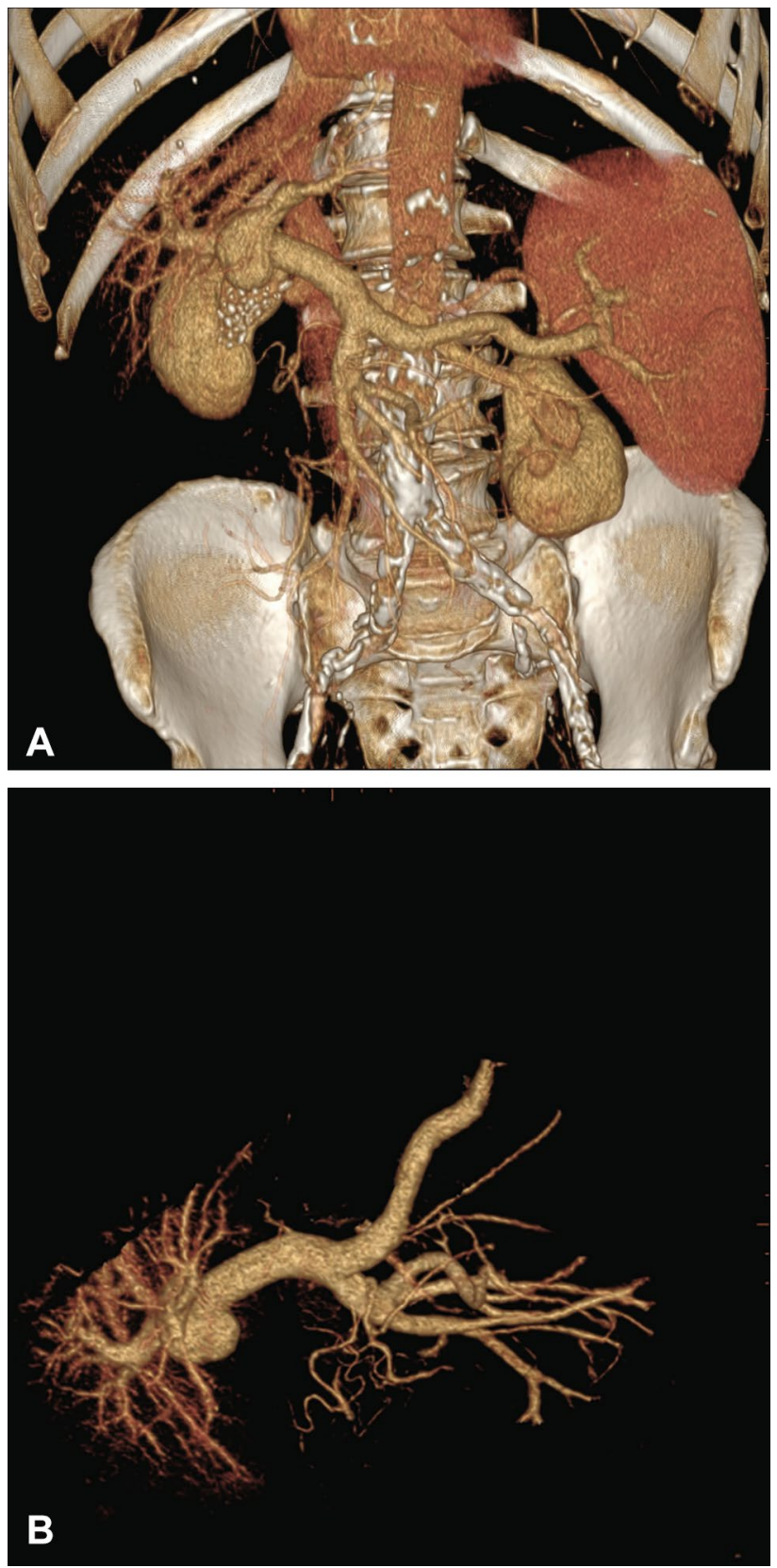

Fig. 3 Abdominal CT angiography with 3D reconstructions show the portal vein system and the saccular aneurysm of the distal segment of the portal trunk (A anterior view; B lateral view)

Acquired aneurysms are generally secondary to portal hypertension in patients with weakening of the venous wall due to high splanchnic flow and hyperdynamic circulation, severe pancreatitis, trauma or invasion of the portal vein wall by malignancy [9-12].

A potential role of cholecystitis and choledocholithiasis in the portal vein aneurysm development has been suggested by some authors [13], but these data have not been confirmed. 
The acquired forms may affect the main portal trunk, portal bifurcation and intrahepatic portal branches and are generally asymptomatic (about $30 \%$ ) or paucisymptomatic in $50 \%$ of cases and associated with mild and nonspecific abdominal pain [3, 14].

Literature data have shown that only less than $10 \%$ of patients present with gastrointestinal bleeding, jaundice due to biliary tract compression, duodenal compression or inferior vena cava obstruction, whereas about $20 \%$ may be complicated by thrombosis [1].

Only one case reported by Khairallah et al. described the presence of wall calcifications within the intima and media of portal vein aneurysm due to mechanical stress [15]. In patients with portal hypertension, compensatory intimal thickening and medial hypertrophy may be observed. The medial hypertrophy may be associated with the deposition of fibrous tissue that weakens the wall and, rarely, calcifications.

Intrahepatic portal vein aneurysms are generally smaller than extrahepatic aneurysms and no correlations have been demonstrated with age or sex [16].

In 2015 Laurenzi et al. reported, in their overview of the international literature, only 96 case reports including 190 patients with portal vein thrombosis [1]. Liver cirrhosis was found in $26 \%$ and portal hypertension in $32 \%$ of patients. Concerning the aneurysm localization, about $80 \%$ involved the main portal trunk, portal bifurcation or intrahepatic branches, whereas $20 \%$ affected the spleno-mesenteric confluence.

In the medical literature, only a few cases reported spontaneous rupture or regression of the portal vein aneurysms. Priadko et al. recently described 3 cases of asymptomatic portal vein aneurysms with no progression in dimension during a long-term follow-up [3].

Treatment options, conservative management or surgery, should be considered case by case.

Currently, in asymptomatic patients with small portal vein aneurysms, conservative management with regular ultrasound follow-up (every 6 months) is acceptable. The management of patients with large but asymptomatic aneurysms is questionable because a surgical approach should be considered taking into account the coexistence of portal hypertension and, if any, other liver-related clinical issues such as decompensation or kidney failure [17].

Surgical treatment is the recommended strategy in cases of symptomatic patients without portal hypertension showing abdominal pain, biliary tract compression, enlarging aneurysms with risk of spontaneous rupture or in case of rupture [18].

In these patients, aneurysmorrhaphy or aneurysmectomy, according to the type of aneurysm (saccular or fusiform), are the treatments of choice. In patients without portal hypertension, these procedures may be considered a definitive treatment because portal vein aneurysm is generally congenital and no liver disease or portal hypertension coexist [1].

In patients with liver cirrhosis complicated by portal hypertension and criteria for surgical management, shunting and liver transplantation are considered as treatment options due to the high risk of surgical mortality. In this case, the aim is to decompress the portal system to prevent the dilation of the aneurysm $[1,17]$.

Recently, some authors have proposed the use of transjugular porto-systemic shunt (TIPS) or embolization as new treatment approaches.

Ding et al. described a case of 70-mm aneurysmal dilation of the distal portal vein involving the left and right branches in a 48-year old man with hepatitis B-related cirrhosis. The patient had undergone a splenectomy because of upper gastrointestinal hemorrhage and, after portal aneurysm diagnosis, he was treated with a TIPS to prevent its progressive dilation. At the 6-month follow-up the aneurysm was decreased and, after 2 years, disappeared [19].

Shukla et al. reported the case of a rapidly growing saccular intrahepatic portal vein aneurysm $(3 \mathrm{~cm})$ in a 55 -year-old man. Percutaneous embolization successfully occluded the aneurysm and prevented further growth and complication [20].

Finally, Tsuo et al. observed a saccular aneurysm at the extrahepatic portal vein main trunk $(3 \mathrm{~cm})$ in a 65 -year-old woman with Budd-Chiari syndrome and abdominal pain. TIPS was created with a significant decrease in the aneurysm size (1.9 $\mathrm{cm}$ after 1 year) [21].

\section{Conclusion}

Portal vein aneurysms are rarely observed in clinical practice, therefore, no definite data are available on natural history, risk of complications and treatment. In all cases reported in literature, abdominal ultrasound played a pivotal role being the first diagnostic approach for the identification, evaluation of size and complications, and long-term followup. The use of Color Doppler US with the typical "Korean flag" or "Yin-Yang" flow pattern may provide crucial information and help the identification of portal vein aneurysms and thrombosis. Undoubtedly, ultrasonography and Color Doppler US are excellent tolls for the diagnosis and followup of portal vein aneurysms.

Funding No funding was received.

\section{Declarations}

Conflict of interest The authors declare that they have non conflict of interest. 
Ethical approval All procedures performed in this studies involving human participants were in accordance with the ethical standards of the institutional and/or national research committee and with the 1964 Helsinki declaration and its later amendments or comparable ethical standards.

Informed consent Informed consent was obtained from the patient included in the study. A written permission was obtained from the patient.

Open Access This article is licensed under a Creative Commons Attribution 4.0 International License, which permits use, sharing, adaptation, distribution and reproduction in any medium or format, as long as you give appropriate credit to the original author(s) and the source, provide a link to the Creative Commons licence, and indicate if changes were made. The images or other third party material in this article are included in the article's Creative Commons licence, unless indicated otherwise in a credit line to the material. If material is not included in the article's Creative Commons licence and your intended use is not permitted by statutory regulation or exceeds the permitted use, you will need to obtain permission directly from the copyright holder. To view a copy of this licence, visit http://creativecommons.org/licenses/by/4.0/.

\section{References}

1. Laurenzi A, Ettorre GM, Lionetti R, Meniconi RL, Colasanti M, Vennarecci G (2015) Portal vein aneurysm: what to know. Dig Liver Dis 47(11):918-923

2. Koc Z, Oguzkurt L, Ulusan S (2007) Portal venous system aneurysms: imaging, clinical findings, and a possible new etiologic factor. AJR Am J Roentgenol 189(5):1023-1030

3. Priadko K, Romano M, Vitale LM, Niosi M, De Sio I (2021) Asymptomatic portal vein aneurysm: three case reports. World J Hepatol 13(4):515-521

4. Flis V, Gadzijev E (2003) Reconstruction of the main portal vein for a large saccular aneurysm. HPB (Oxford) 5(3):188-190

5. Ohnishi K, Nakayama T, Saito M, Nomura F, Koen H, Tamaru J et al (1984) Aneurysm of the intrahepatic branch of the portal vein. Rep Two Cases Gastroenterol 86(1):169-173

6. Lopez-Machado E, Mallorquin-Jimenez F, Medina-Benitez A, Ruiz-Carazo E, Cubero-Garcia M (1998) Aneurysms of the portal venous system: ultrasonography and CT findings. Eur J Radiol 26(2):210-214

7. Gallego C, Velasco M, Marcuello P, Tejedor D, De Campo L, Friera A (2002) Congenital and acquired anomalies of the portal venous system. Radiographics 22(1):141-159

8. Sari IK, Cosar R, Yilmaz S, Demirci H (2018) Klinefelter syndrome with portal vein aneurysm: case report. Gazi Med J 29(1):80-81
9. Schwope RB, Margolis DJ, Raman SS, Kadell BM (2010) Portal vein aneurysms: a case series with literature review. J Radiol Case Rep 4(6):28-38

10. Cheng XQ, Zuo CJ, Tian JM, Liu Q, Liu JP, Wang L et al (2010) Portal vein aneurysms with multiple associated findings. Vasa 39(4):312-318

11. Lau H, Chew DK, Belkin M (2002) Extrahepatic portal vein aneurysm: a case report and review of the literature. Cardiovasc Surg 10(1):58-61

12. Yang DM, Yoon MH, Kim HS, Jin W, Hwang HY, Kim HS (2001) CT findings of portal vein aneurysm caused by gastric adenocarcinoma invading the portal vein. Br J Radiol 74(883):654-656

13. Kurtcehajic A, Alibegovic E, Hujdurovic A, Vele E, Kurtcehajic D (2018) Role of cholelithiasis in development of portal vein aneurysm. Am J Med 131(3):e119

14. Kurtcehajic A, Vele E, Hujdurovic A (2016) Portal vein aneurysm and portal biliopathy. J Hepatobiliary Pancreat Sci 23(10):658

15. Khairallah S, Elmansouri A, Jalal H, Idrissi MO, Ganouni NC (2016) Calcified wall portal venous aneurysm: a case report. Pan Afr Med J 25:93

16. Watanabe Y, Takase K, Okada K, Aikawa M, Okamoto K, Koyama I (2020) Portal vein aneurysm with complete spontaneous regression after 10 years using conservative treatment. Clin J Gastroenterol 13(5):940-945

17. Jaiswal P, Yap JE, Attar BM, Wang Y, Devani K, Jaiswal R et al (2017) Massive asymptomatic extrahepatic portal vein aneurysm. Am J Med 130(9):e383-e386

18. De Vloo C, Matton T, Meersseman W, Maleux G, Houthoofd S, de Beeck KO et al (2019) Thrombosis of a portal vein aneurysm: a case report with literature review. Acta Clin Belg Int J Clin Lab Med 74(2):115-120

19. Ding PX, Han XW, Hua ZH (2017) Extrahepatic portal vein aneurysm at the portal bifurcation treated with transjugular intrahepatic portosystemic shunt. J Vasc Interv Radiol 28(5):764-766

20. Shukla PA, Kolber MK, Kumar A, Patel RI (2016) Percutaneous embolization of an intrahepatic portal vein aneurysm. J Vasc Interv Radiol 27(11):1747-1749

21. Tsauo JW, Li X (2015) Portal vein aneurysm associated with Budd-Chiari syndrome treated with transjugular intrahepatic portosystemic shunt: a case report. World J Gastroenterol 21(9):2858-2861

Publisher's Note Springer Nature remains neutral with regard to jurisdictional claims in published maps and institutional affiliations. 